\title{
Long-term stability of the final slopes of the mining waste dumps from Oltenia
}

\author{
Maria Lazar $^{1}{ }^{*}$, Florin Faur ${ }^{1}$, Izabela-Maria Apostu ${ }^{1}$, and Constantin Rada $^{1}$ \\ ${ }^{1}$ University of Petrosani, Department of Environmental Engineering and Geology, University Street, \\ no. 20, Petrosani, Romania
}

\begin{abstract}
The waste dumps resulted from the lignite exploitation activities from Oltenia are constructions that reach, in most cases, impressive dimensions and store large volumes of sterile rocks. Usually, the dumps are arranged and ecologically restored, but between the moment of their release from technological tasks and the beginning of the arrangement works, periods of time, measured even in years, can pass. The calculations regarding the geometry of the waste dumps are performed in the design stage, taking into account the mechanical strength characteristics of the mixture of sterile material that forms them, so as to ensure a sufficient stability reserve during the construction period and when the projected storage capacity is achieved. If the arrangement and ecological restoration works do not start immediately after the depositing activity is stopped, the exposure of loose and disaggregated material to the influence of external factors (especially erosion and rainfall infiltration) can lead to landslides with disastrous consequences on natural and anthropogenic objectives located in the influence area. This paper analyzes the stability elements of waste dumps under normal operating conditions, the modification of the strength characteristics over time and the geometry required in the final phase so as to ensure their long-term stability.
\end{abstract}

\section{Introduction}

The stability of slopes in the case of open-pit exploitation of useful substances is one of the most important issues, both during operation (active period of open pits) and after their closure. Ensuring the stability of dumps in the short, medium and long term is one of the most difficult tasks for both designers and mining operators. The dumps are originally constructed of a mixture of loose rocks, often with higher humidity than the undisturbed material. By excavation, the cohesion is destroyed and as a result, the physical-mechanical parameters of the mixture are different from those of the "in situ" rocks [1]. When designing the geometry of dumps, the characteristics of the material mixture, the characteristics of the location and the method of deposition, the final volume of the dump, etc. are usually taken into account.

\footnotetext{
*Corresponding author: marialazar@upet.ro
} 
Sliding of dumps slopes can have multiple causes, including incorrect sizing and/or non-compliance with the projected geometry, the action of triggering factors that were not taken into account in the design process, the failure of the base terrain, etc.

For the correct estimation of the stability conditions of the dumps, complex research is required, in particular, regarding the nature of the dumped rock mixture and its strength characteristics. The introduction in the stability analyses of some correct values of the physical-mechanical properties of the rocks is only a premise for obtaining some covering results for the stability coefficient. It must be taken into account that we work with values that are valid at the time of calculations, values that change over time, especially due to the influence of external factors (such as erosion, water infiltration into the body of dumps, the appearance of overloads on the upper platform of the dump, or the action of mechanical shocks that are transmitted in the form of seismic waves) or as a result of rheological processes that cause major changes in the state of stress and tension and accentuation of deformations. The deformation rate increases significantly in periods of heavy rainfall, which coincide with the snow-melting period, due to the increase in moisture of the material mixture, when it becomes thick plastic and/or soft plastic.

\section{Materials and methods}

\subsection{Open-pit mining exploitation of lignite in Oltenia}

The Oltenia mining basin is located in the south of the Southern Carpathians and the systematized mining of lignite in Oltenia began in the middle of the last century, since then significant quantities of lignite being extracted, used to produce electricity and heat, especially in thermal power plants. The main mining sub-basins in which lignite mining is currently concentrated are Rovinari, Motru and Jilț (figure 1).

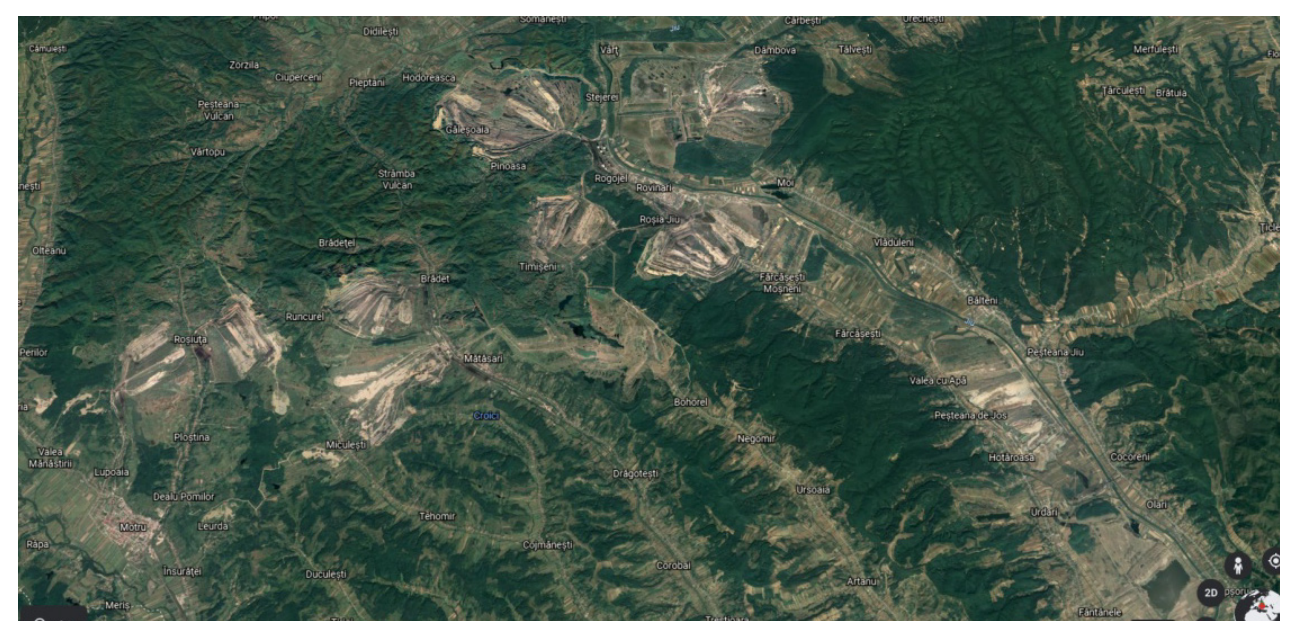

Fig. 1. Rovinari, Motru and Jilț mining basins.

Over time, the activity of lignite mining has been organized in different structures. At present there is an energy complex (Oltenia Energy Complex - OEC) whose purpose is the production of electricity and heat, using as raw material lignite extracted in the open-pits.

Given the characteristics of the lignite deposit (layered, almost horizontal, with sterile intercalations), the exploitation is performed using continuous technological fluxes (bucketwheel excavator, conveyor belts, scrapers), the lignite being transported to deposits or 
directly to thermal power plants, and the waste material to the external and/or internal waste dumps.

Currently, the mining activity is carried out in 12 perimeters ( 9 of them in Jilt, Motru an Rovinari sub-basins) equipped with 118 machines, of which 28 modernized bucket-wheel excavators and $220 \mathrm{~km}$ of conveyor belts, with a production capacity of 25-30 million tons/year. According OEC website, mining began in 1957, and the total lignite production is about 1.6 billion tons. Taking into account an average overburden coefficient, of $4.5 \mathrm{~m}^{3} / \mathrm{t}$, it results that during this period approximately 7.2 billion $\mathrm{m}^{3}$ of waste material were stored in external and internal dumps.

Different mining methods are applied in the open-pits in Oltenia, depending on the local characteristics of the lignite deposit and the development stage of the open-pits. Thus, it was started with the methods of exploitation with the transport of waste rocks to external dumps, and now, in most open-pits, the exploitation methods that are applied involve the partial transport and direct translation of waste material to internal dumps.

As a result of the mining process, several waste dumps have been built, which are in different phases (construction, abandoned with or without conservation measures, arranged, and ecologically restored) [2]. Table 1 presents the main elements of the active dumps in the Jilt, Motru, and Rovinari mining basins.

Table 1. Active dumps in the Jilț, Motru, and Rovinari mining basins (at the end of January 2021).

\begin{tabular}{|c|c|c|c|c|c|c|}
\hline $\begin{array}{l}\text { Mining } \\
\text { basin }\end{array}$ & Open-pit & $\begin{array}{l}\text { Type of } \\
\text { the dump }\end{array}$ & $\begin{array}{c}\text { Volume } \\
\left(\mathbf{x 1 0}^{3} \mathrm{~m}^{3}\right)\end{array}$ & $\begin{array}{c}\text { Surface } \\
\left(\mathrm{m}^{2}\right)\end{array}$ & $\begin{array}{l}\text { Height } \\
\text { (m) }\end{array}$ & $\begin{array}{c}\text { General } \\
\text { slope angle } \\
\left({ }^{\circ}\right) \\
\end{array}$ \\
\hline \multirow{2}{*}{ JILȚ } & Jilț Nord & Internal & 169,205 & $2,990,000$ & 86 & $4^{\circ} 16^{\prime}$ \\
\hline & Jilț Sud & Internal & 286,000 & $5,199,200$ & 95 & $5^{\circ} 25^{\prime}$ \\
\hline \multirow{3}{*}{ MOTRU } & \multirow{2}{*}{ Roșiuța } & Internal & 91,416 & $1,920,400$ & 70 & $6^{\circ} 05^{\prime}$ \\
\hline & & External & 48,129 & $2,246,300$ & 70 & $3^{\circ}$ \\
\hline & Lupoaia & Internal & 352,321 & $5,220,000$ & 93 & $4^{\circ} 60^{\prime}$ \\
\hline \multirow{8}{*}{ ROVINARI } & $\begin{array}{c}\text { Peșteana } \\
\text { Nord } \\
\end{array}$ & Internal & 209,302 & $5,204,400$ & 88 & $3^{\circ} 50^{\prime}$ \\
\hline & \multirow{2}{*}{ Pinoasa } & External & 256,834 & $4,620,000$ & 75 & $3^{\circ} 54^{\prime}$ \\
\hline & & Internal & 58,501 & $1,140,000$ & 70 & $5^{\circ} 25^{\prime}$ \\
\hline & $\begin{array}{c}\text { Roșia de } \\
\text { Jiu }\end{array}$ & Internal & 384,325 & $6,225,000$ & 93 & $2^{\circ} 25^{\prime}$ \\
\hline & \multirow[b]{2}{*}{ Rovinari } & $\begin{array}{l}\text { Internal - } \\
\text { Gârla }\end{array}$ & 222,497 & $3,693,000$ & 70 & $3^{\circ}$ \\
\hline & & $\begin{array}{c}\text { Internal - } \\
\text { Rovinari } \\
\text { Est }\end{array}$ & 339,866 & $4,693,000$ & 96 & $6^{\circ}$ \\
\hline & \multirow{2}{*}{ Tismana } & $\begin{array}{c}\text { Internal - } \\
\text { Tismana II }\end{array}$ & 260,000 & $5,360,000$ & 70 & $1^{\circ} 50^{\prime}$ \\
\hline & & $\begin{array}{l}\text { Internal - } \\
\text { Tismana I }\end{array}$ & 340,000 & $7,400,000$ & 75 & $1^{\circ} 65^{\prime}$ \\
\hline
\end{tabular}

Over time, there have been numerous slides of waste dumps in different stages of construction. These landslides often generate more or less serious consequences on the environment, on the objectives in the area of influence, or on the productive activity. 


\subsection{Waste dumps stability}

The analyses carried out on the waste dumps in Oltenia aimed at ensuring a short-term and possibly medium-term stability reserve, without taking into account their long-term existence and the effect of the time factor on their stability. In fact, an important role in the formation and development of dump slides has the rheological behavior of soils, materialized under two essential aspects: the slow flow (creep) of soils over time, and their long-term resistance, which is reduced in time in close connection with deformations [3].

According to Maslov's theory of slow flow [4, 5], developed based on 3 criteria, the first two have immediate applicability in estimating long-term slope stability:

1. Initial resistance of the soft rocks for $\mathrm{t}=0$ :

$$
\tau_{0}=\sigma \cdot \operatorname{tg} \varphi+\sum_{w}+c_{s}
$$

2. Final resistance (lasting) for $t=\infty$ :

- in conditions of maintaining the structural cohesion overtime:

$$
\tau_{\infty}=\sigma \cdot \operatorname{tg} \varphi+c_{S}
$$

- in conditions of the destruction of the structural cohesion as a result of high deformation of soft rocks:

$$
\tau_{\infty}=\sigma \cdot \operatorname{tg} \varphi
$$

3. Conditions which must be fulfilled at same time for the occurrence of slow flow:

$$
\tau<\sigma \cdot \operatorname{tg} \varphi+\sum_{w} c_{s} \text { and } \tau>\sigma \cdot \operatorname{tg} \varphi+c_{s}
$$

where:

$\sigma \cdot \operatorname{tg} \varphi$ - internal friction angle;

$\sum_{w}$ - hydrocolloidal cohesion;

$c_{s}$ - rigid structural cohesion.

Slope slides can be defined as three-phase rheological processes [6]:

- slow slide, characterized by successive local failures and the formation of the slide surface, which can last as long as there is no movement in the slope;

- the actual slide, respectively a very large displacement in a very short time;

- stabilized slide, which is characterized by small displacements and local reactivation of slides.

The mechanical strength characteristics are reduced overtime under the action of external factors so that the stability reserve of slopes with a long residence time must be determined or imposed in order to avoid the sliding phenomena that may occur in time. The specialized literature indicates for slopes with a height of $10 \mathrm{~m}$ made from montmorillonitic clays a slope angle of $18-20^{\circ}$ to ensure its stability for a period of up to 10 years [6]. The influence of time on the stability of waste dumps is major especially if the pores of the mixture of dumped material are filled with water and pore water pressure is generated. The water content in rocks changes both the strength and the elastic characteristics of the rocks, the cohesion, the internal friction angle, the deformation characteristics, etc. In the case of clayey rocks, the effect of increasing humidity is not reversible, because there are alteration phenomena that contribute to reducing the breaking strength [7].

All these aspects must be taken into account from the design stage of waste dumps, which are engineering constructions with a long residence time. If for the rocks from some mining perimeters of underground coal exploitation there were researches for determining the rheological behavior of the rocks [8], for the mining exploitations from Oltenia the phenomenon has not been studied enough. 
Therefore, in order to assess the stability reserve required for waste dumps in Oltenia, analysis methods based on the equilibrium limit theory were used in this paper and the above considerations related to the influence of time (manifested in particular by repeated phenomena of precipitation infiltration and the development of pore water pressure) were taken into account (as effects on the strength properties of the mixture of rocks).

\section{Results and discussion}

The mixture of rocks from the Oltenia dumps consists predominantly of clays, sands, dust, and gravel with different participations even in the case of the same dump [9].

For the case study, the external dump of the Roșiuța open-pit, from the Motru mining basin, was chosen, respectively Valea Știucani, which is an active dump and currently stores a volume of over 48 million $\mathrm{m}^{3}$ of waste material, with a total height of $70 \mathrm{~m}$ (figure 2).

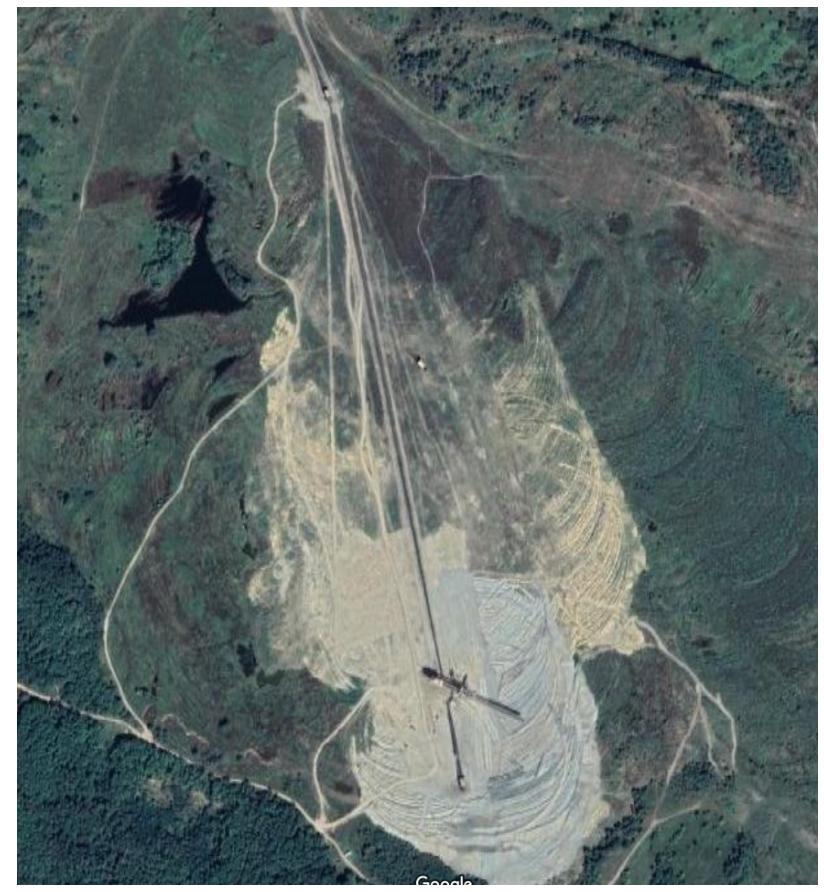

Fig. 2. Valea Știucani waste dump.

The dump was designed for a final height of $120 \mathrm{~m}$, consisting of 8 steps with an individual height of $15 \mathrm{~m}$ and an inclination of $26^{\circ}$.

Based on the samples collected from the boreholes performed over time and the determinations performed in the laboratory, respectively granulometry, plasticity index, consistency index (state index), cohesion and mineralogical composition, the rocks participating in the composition of Valea Ştiucani dump, have the following share [2]:

- non-cohesive rocks - sandy rocks - 30\%;

- weakly cohesive rocks - dusty rocks - dust, clayey-dusty sands - 31\%;

- cohesive rocks - represented mainly by rocks of clayey nature (the whole range of clayey rocks, respectively dusty clays, marly clays, greasy clays, carbonaceous clays) $39 \%$. 
The results of the statistical data processing regarding the physical-mechanical characteristics determined in the laboratory on samples taken from three boreholes executed in the Valea Știucani dump are presented in Table 2.

Table 2. Representative characteristics of waste material deposited in Valea Știucani dump.

\begin{tabular}{|c|c|c|c|c|}
\hline Borehole & F1 & F2 & F3 & Average \\
\hline Characteristics & 27.00 & 26.27 & 27.19 & 26.82 \\
\hline $\begin{array}{c}\text { Specific weight } \\
\gamma_{\mathrm{s}}\left(\mathrm{kN} / \mathrm{m}^{3}\right)\end{array}$ & 18.99 & 18.13 & 18.61 & 18.58 \\
\hline $\begin{array}{c}\text { Volumetric weight } \\
\gamma_{\mathrm{v}}\left(\mathrm{kN} / \mathrm{m}^{3}\right)\end{array}$ & 31.92 & 29.99 & 33.92 & 31.94 \\
\hline $\begin{array}{c}\text { Natural moisture } \\
\mathrm{W}(\%)\end{array}$ & 49.05 & 46.89 & 48.66 & 48.20 \\
\hline $\begin{array}{c}\text { Porosity } \\
\mathrm{n}(\%)\end{array}$ & 0.96 & 0.88 & 0.95 & 0.93 \\
\hline $\begin{array}{c}\text { Pore index } \\
\varepsilon\end{array}$ & 0.89 & 0.89 & 0.96 & 0.91 \\
\hline $\begin{array}{c}\text { Saturation coefficient } \\
\mathrm{s}\end{array}$ & 0.28 & 0.25 & 0.16 & 0.23 \\
\hline $\begin{array}{c}\text { Cohesion } \\
\mathrm{c}\left(\text { daN/cm }{ }^{2}\right)\end{array}$ & 14.27 & 17.28 & 11.62 & 14.39 \\
\hline $\begin{array}{c}\text { Internal friction angle } \\
\varphi\left({ }^{\circ}\right)\end{array}$ & & &
\end{tabular}

Analyzing the values presented in the table, as well as the description of the material taken from boreholes [10] results the following conclusions:

- the humidity of the waste rocks is high, as a result of the high water retention capacity of the clayey rocks;

- the specific and volumetric weights $\left(\gamma_{\mathrm{s}}\right.$ and $\left.\gamma_{\mathrm{v}}\right)$ have limited fields of variation, which reflects a fairly high homogeneity of the material in terms of structure and even in terms of compaction;

- the porosity of the dumped rocks (n) is between $47-49 \%$ and indicates a high water storage capacity in the pores of the dumped rocks, and the pore index, $\varepsilon=0.88 \div 0.96$, indicates moderate settlements;

- in terms of mechanical strength characteristics, different values of cohesion and internal friction angle were recorded within the same geotechnical borehole, which demonstrates, on the one hand, the structural heterogeneity of the material and, on the other hand, the presence of areas of minimum resistance in which stress states are created that can cause irreversible deformations of the dumped rocks. These areas can be defined as areas of plastic release of clayey rocks under the influence of the weight of the dumped rocks.

The physical characteristics of the dumped rocks and their nature indicate that the rocks identified in the 3 boreholes are prone to thixotropy and liquefaction.

The appearance of thixotropy creates the instability of the rock by reducing the shear strength with a coefficient called the shear strength reduction coefficient, given by the ratio between the shear strength in the thixotropic state and the one in the natural state. When the thixotropy phenomenon appears, the clayey rocks reduce their resistance by about $50 \%$. Liquefaction of rocks is a phenomenon characteristic of clayey-dusty or sandy rocks saturated with water. This phenomenon occurs due to the increase of the pore water pressure and the decrease of the shear strength. The first parameter that favors liquefaction is the pore index. Another very important parameter is adsorbed-absorbed water. It occurs in clayey-dusty rocks, which leads to their plasticization and can liquefy only under the 
action created by the weight of the covering rocks. As a result, the determined values and the reduced values of the mechanical strength characteristics of the mixture of rocks in the dump were taken into account in the stability calculations.

The stability analyses were performed using the specialized software SLOPE (Janbu's simplified method), and among the objectives included were the verification of the stability conditions of the individual dump steps and the establishment of the dependence between humidity and stability over time. The results obtained for the designed geometric elements of the dump steps are shown in Figures 3-6 and Table 3.

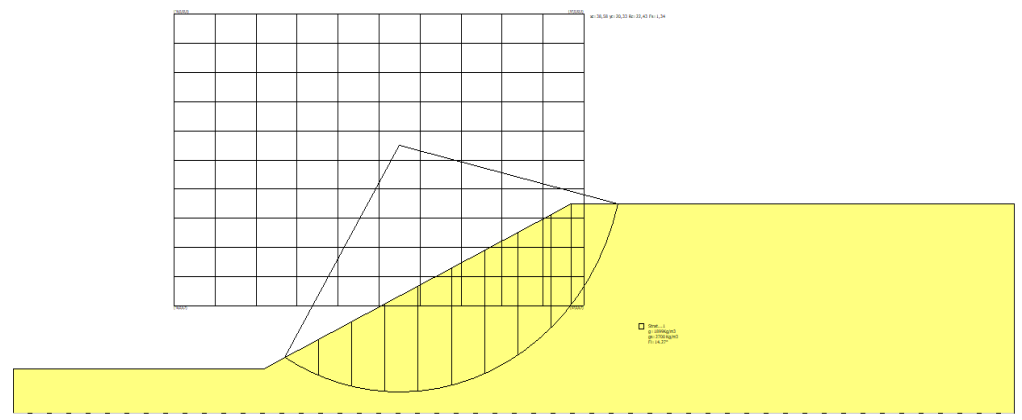

Fig. 3. Stability analysis corresponding to F1.

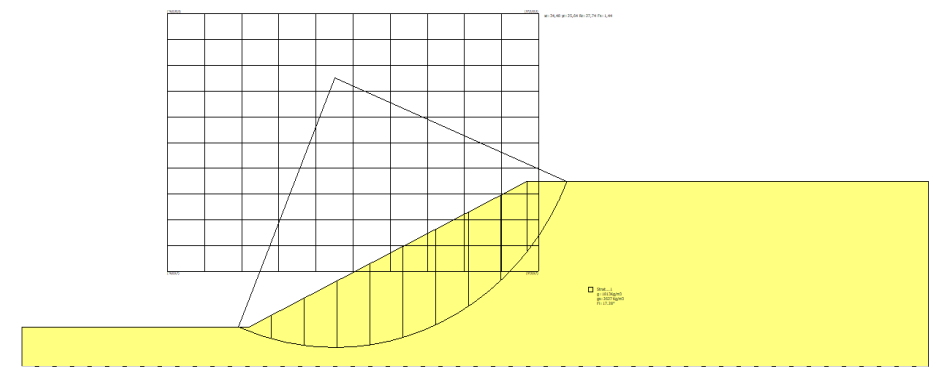

Fig. 4. Stability analysis corresponding to F2.

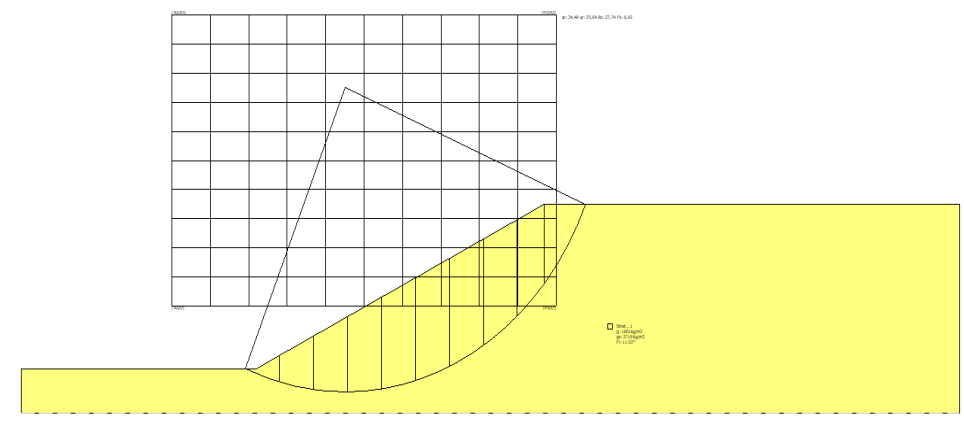

Fig. 5. Stability analysis corresponding to F3. 


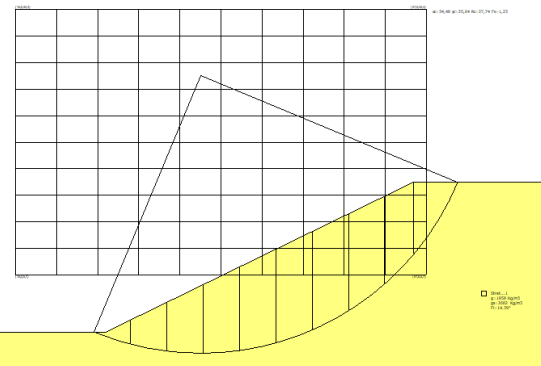

Fig. 6. Stability analysis corresponding to the average values.

Table 3. Stability analyses results.

\begin{tabular}{|l|c|c|c|}
\hline \multirow{2}{*}{ Borehole } & \multirow{2}{*}{$\begin{array}{c}\text { Humidity } \\
\text { W (\%) }\end{array}$} & \multicolumn{2}{c|}{$\begin{array}{c}\text { Stability coefficient } \\
\text { s }\end{array}$} \\
\cline { 3 - 4 } & & Determined cohesion & Reduced cohesion \\
\hline F1 & 31.92 & 1.34 & 0.99 \\
\hline F2 & 29.99 & 1.44 & 1.10 \\
\hline F3 & 33.92 & 0.92 & 0.72 \\
\hline Average & 31.94 & 1.23 & 0.94 \\
\hline
\end{tabular}

It is observed that when only structural cohesion is considered to be maintained over time, taking into account Maslov's $2^{\text {nd }}$ criterion and the thixotropic behavior of clayey rocks, the stability coefficient is reduced by about $25 \%$. Based on the data in Table 3 , the dependence between the rock humidity (which proved to be up to saturation limit) and the stability coefficient calculated for the determined cohesion was established, as shown in Figure 7.

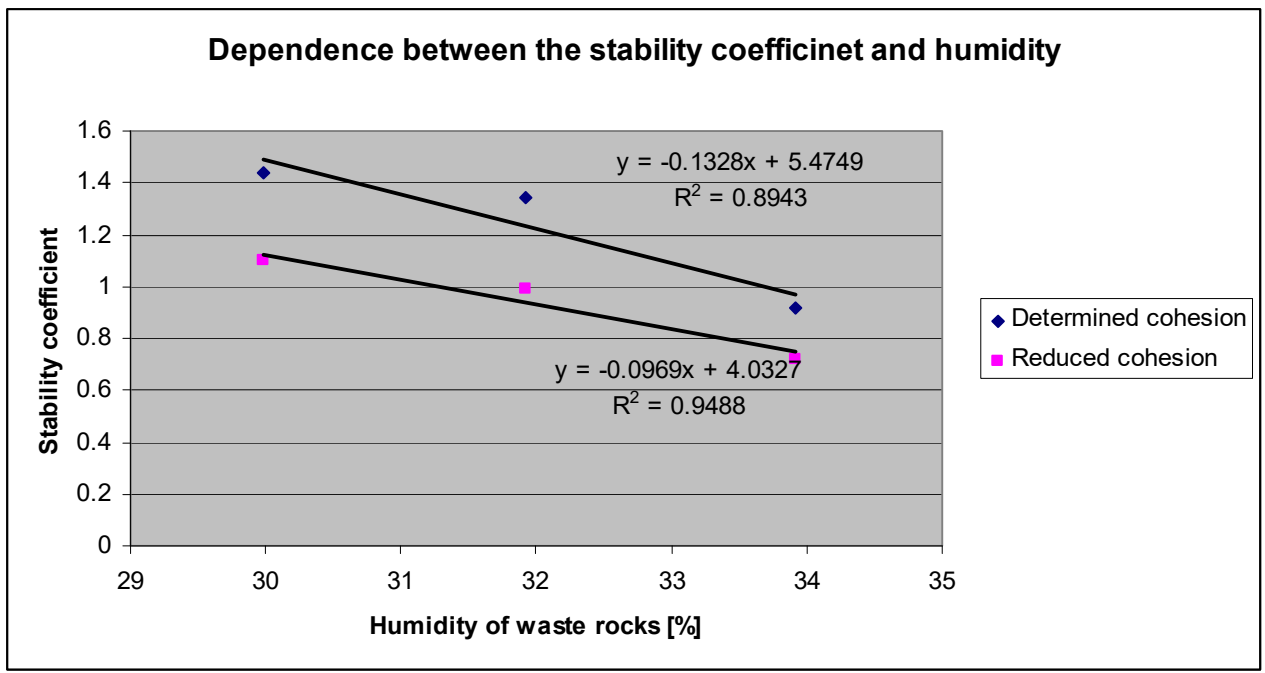

Fig. 7. Dependence between the stability coefficient and the rocks humidity.

From the analyses performed, it is clear that the humidity of the rocks in the waste dump greatly influences the stability reserve, causing a substantial reduction of it over time, as it can be seen in Figure 7. 
As waste dumps store large volumes of tailings and their slide endangers all objectives located in their area of influence, a safety factor of 1.3 (equivalent to a $30 \%$ stability reserve) is currently recommended. However, given the fact that over time there are deformations in the body of waste dumps and, at the same time, significant amounts of water infiltrate from precipitation (due to the degree of loosening of the waste material), and the stability reserve decreases by about $25 \%$, rethinking the sizing of the geometry, as well as increasing the required long-term stability reserve to at least $50 \%$, especially in the case of large dumps, is required.

\section{Conclusions}

The waste dumps from Oltenia are engineering constructions that incorporate large volumes of waste material resulting from lignite open-pits (some of them store over 350 million $\mathrm{m}^{3}$ ). Although the stable design of dumps has always been a major issue in the practice of openpit mining perimeters, very little emphasis has been placed on the rheological characteristics of the dumps and their behavior over time. By addressing this issue, the research team aimed at highlighting the rheological processes that, in fact, lead to the deformation and failure of the dumps and the need for detailed studies of the dumps from this point of view. The results show that ensuring a stability reserve of $30 \%$ is insufficient if such constructions, whose slide can endanger the natural and anthropogenic environment, lose their stability and significant masses of rocks are displaced.

\section{References}

1. M. Lazar, Stability and Ecological Reconstruction of the Land Affected by Mining. Reports of Professorship Surface Mining, Vol. 63 (Medienzentrum TU BA Freiberg, 2017).

2. ***, Design documentation and geotechnical studies elaborated by the Institute of Scientific Research Technological Engineering and Mining on Lignite (in Romanian), Craiova, Romania.

3. C. Marinescu, Ensuring the stability of embankments and slopes (in Romanian), Vol. 1 and 2 (Tehnical PH, Bucharest, 1988).

4. N.N. Maslov, Landslides and their control (in Russian) (Stroyizdat, Moscow, 1977).

5. N.N. Maslov, Physical and technical theory of clay soils creep in practice construction. (Stroyizdat, Moscow, 1984).

6. A. Todorescu, Reologia rocilor cu aplicații in minerit (Rocks rheology with applications in mining) (Tehnical PH, Bucharest, 1986).

7. A. Todorescu, Proprietățile rocilor (Rocks properties) (Tehnical PH, Bucharest, 1984).

8. M. Toderaş, Rocks rheology in the stability of underground mining works. Study case: Sedimentary rocks from Jiu Valley, Romania (Saarbrücken, Germany - Scholars' Press International Publishing House, Lambert Academic Publishing, OmniScriptum GmbH \& Co. KG Germany, 2015).

9. I. Rotunjanu, M. Lazar, Revista Construcțiilor (Constructions Revue), 95 (2013).

10. M. Lazar, I. Rotunjanu ș.a. Complex system for monitoring the hydrostatic level in the body of dumps (in Romanian), Scientific research contract No. 1224/S/2006 concluded with SNL Oltenia (2006). 